\title{
Dielectric Barrier Discharge Atomizer for Mercury Speciation by HPLC-CVG Atomic Fluorescence Spectrometry
}

\author{
Lanlan Jin ${ }^{\mathrm{a}}$, Shanshan Yuan ${ }^{\mathrm{b}}$, Ming $\mathrm{Li}^{\mathrm{b}}$, Zhi Xing• ${ }^{\text {a,b }}$, Zhifu Liu ${ }^{\mathrm{a}}$, and Shenghong $\mathrm{Hu}^{\mathrm{a}}$ \\ ${ }^{a}$ State Key Laboratory of Biogeology and Environmental Geology, \\ China University of Geosciences, Wuhan 430074, P. R. China \\ b Department of Chemistry, Tsinghua University, Beijing 100084, P. R. China
}

\section{INTRODUCTION}

With the increase in environmental problems such as pollutant leakage and the pollution of land, water, and the atmosphere, the demand for field analysis has increased significantly and the need for developing a portable/ miniaturized instrument has become very important (1). Compared with the commonly used atomic absorption spectroscopy techniques of AAS, ICP-OES/MS (217), atomic fluorescence spectrometry (AFS) which offers high sensitivity, uses simple instrumentation with low acquisition and running costs $(18,19)$ and has been widely used in various fields for trace heavy metal analysis, especially mercury. As is well known, mercury is regarded as the most hazardous and toxic contaminant (20, 21). Its transportation and other biogeochemical behaviors have an intimate relation with the mercury chemical forms (22-26). Conventionally, the chemical vapor generation atomic fluorescence spectrometry (CVG-AFS) technique combined with high-performance liquid chromatography (HPLC) are extensively used in mercury speciation (27-33); thus integrating the advantages of separation technology and sensitive element-selective detectors (34, $35)$. However, the current commercial atomizer of CVG-AFS is not enclosed and can produce high temperature. It requires a lot of room space to protect the instrument from the high temperature

Corresponding autbor.

E-mail: xingz@mail.tsingbua.edu.cn Tel: +861062781687

\begin{abstract}
A portable, miniaturized atomizer-based dielectric barrier discharge (DBD) device was developed for the simultaneous speciation of mercury into inorganic mercury $\left(\mathrm{Hg}^{2+}\right)$, methylmercury (MeHg), and ethylmercury (EtHg) by HPLC-CVGAFS. The analytical performance as well as the optimum separation and detection conditions of the modified methodology were evaluated. Using the optimized conditions, the minimum quantitative limits obtained were 0.084 , $0.086,0.093 \mu \mathrm{g} \mathrm{L}^{-1}$ for $\mathrm{Hg}^{2+}$, $\mathrm{MeHg}$ and EtHg, respectively. The relative standard deviations (RSDs, $\mathrm{n}=7$ ) from $8 \mu \mathrm{g} \mathrm{L}^{-1} \mathrm{Hg}^{2+}$, $\mathrm{MeHg}$, and EtHg were 3.7\%, $4.8 \%$, and $3.9 \%$, respectively. In addition, the certified reference material GBW10029 Fish was used to verify the feasibility and potential of the new atomizer for the speciation of $\mathrm{Hg}$ on-line and in the field.
\end{abstract}

and is, therefore, not suitable for the development of a portable instrument for field analysis (3638). Undoubtedly, the atomizer is a key issue in miniaturizing atomic spectrometry as well as being a crucial part of the AFS system (1). Recently, the nonthermal-plasma devices based on dielectric barrier discharges (DBD) have gained the attention in analytical spectrometry (39-41) owing to its low power consumption, low cost of fabrication, ambient-temperature operation, as well as miniaturization (37, 42, 43). In addition, the DBD devices can provide free radicals and other activated particles, which have been implemented in the form of an atomizer for atomic absorption (AAS) (40, 44-47) and fluorescence (AFS) spectrometry $(36,37$, 48, 49). Nevertheless, it is rare to be able to use on-line determination of mercury species with a DBD atomizer (50).

After considering all of these options, a new methodology for mercury speciation ( $\mathrm{MeHg}$, EtHg, and $\mathrm{Hg}^{2+}$ ) by HPLC-CVG-AFS with a miniaturized DBD atomizer was developed and is presented in this paper. Compared to the commonly used techniques based on the cold AFS and CVG-AFS, the signal stability of mercury atomic vapor is almost not influenced by water with the HPLC-CVG-DBD-AFS whose minimum quantitative limit (LOQ) is lower than with a commercial atomizer. Furthermore, the analytical performance as well as the optimum separation and detection conditions of the modified methodology were evaluated and verified using the certified reference material GBW10029 Fish and shows the feasibility and potential of this newly developed method for in-house laboratory and field analysis use.

\section{EXPERIMENTAL}

\section{Instrumentation}

As shown in Figure 1, the DBD atomizer consists of three concentric quartz tubes as follows: (a) the outermost layer supplies shield gas to isolate the outside air for the AFS signal, (b) the secondary outer layer is wrapped with aluminum foil which acts as an external electrode of the discharge reactor, (c) the 
inner tube is inserted with a copper bar as the internal electrode. The DBD pulse generators (DC voltage, $5 \mathrm{~W})$ were purchased from Coronalab Co. Ltd., Nanjing, P.R. China. The model LC-AFS9560 HPLC-AFS instrument employed for this study was obtained from Beijing Haiguang Instrument Co. Ltd., Beijing, P.R. China. The HPLC effluent was introduced directly into the CVG reactor with a Venusil MP C18 separation column ( $4.6 \mathrm{~mm} \times 150 \mathrm{~mm}$, BonnaAgela Technologies, Tianjin, P.R China) using an $\mathrm{HCl}$ solution and sodium borohydride $\left(\mathrm{KBH}_{4}\right)$, then the analyte volatile species were delivered to the DBD atomizer for determination.

\section{Materials and Reagents}

All of the reagents were of analytical-reagent grade. Water was purified by a water purification system (Nanopure ${ }^{\circledR}$, Thermo Scientific, Germany). $\mathrm{A} \mathrm{KBH}_{4}$ solution was prepared daily by dissolving $0.2 \%$ $\mathrm{KBH}_{4}$ (Tianjin Institute of Chemical Reagents Tianjin, P.R. China) in a $0.5 \%(\mathrm{w} / \mathrm{v}) \mathrm{NaOH}$ solution (Beijing Chemicals Co., P.R. China). The 5\% (v/v) $\mathrm{HCl}$ solution was used as the carrier solution and as the medium for subsequent chemical vapor generation (Beijing Chemicals Co., P.R. China). A K $\mathrm{K}_{2} \mathrm{~S}_{2} \mathrm{O}_{8}$ solution was also prepared daily by dissolving $0.2 \%$ $\mathrm{K}_{2} \mathrm{~S}_{2} \mathrm{O}_{8}$ (Tianjin Institute of Chemi- cal Reagents Tianjin, P.R. China) in a $0.5 \%(w / v) ~ N a O H$ solution (Beijing Chemicals Co., P.R. China). A stock solution of $700 \mathrm{mg} \mathrm{L}^{-1} \mathrm{MeHg}$ and $\mathrm{EtHg}, 1000 \mathrm{mg} \mathrm{L}^{-1} \mathrm{Hg}^{2+}$, and the certified reference material GBW 10029 Fish were obtained from the National Research Center for Standard Materials (NRSCM, Beijing, P.R. China). The working solutions of $\mathrm{MeHg}$, $\mathrm{EtHg}$, and $\mathrm{Hg}^{2+}$ were prepared by stepwise dilution of the stock solution in the mobile phase. Argon (99.99\%) (Praxair Inc., Beijing, P.R. China) was used as the carrier and shield gas.

\section{RESULTS AND DISCUSSION}

\section{Optimization of DBD Atomizer}

The carrier gas of the DBD system not only acts as a discharge gas for the generation of the DBD plasma, but is a carrier gas for transporting the hydrides into the discharge place. In general, the chemical vapor concentration can be diluted when the carrier gas flow rate is too large. When the carrier gas flow rate is too small, it is difficult to bring the chemical vapor quickly into the atomizer for atomization as well as have an effect on the discharge, which may reduce the intensity of fluorescence and cause the phenomenon of signal trailing. Hence, after further investigation, the optimum signalto-background ratio was found at a flow rate of $500 \mathrm{~mL} \mathrm{~min}-1$ as shown in Figure 2.

The height of the DBD atomizer has also an intimate relation with the atomization efficiency of the $\mathrm{MeHg}$, EtHg, and $\mathrm{Hg}^{2+}$ species as well as the background value. The appropriate height is helpful to maintain high sensitivity. As shown in Figure 3, a desirable fluorescence intensity signal and background value were obtained when the atomizer is $15 \mathrm{~mm}$ high.

Plasma power is another factor affecting dielectric barrier discharge which was also evaluated as shown in Figure 4 . It can be seen that the DBD system has high atomization efficiency for the mercury species with a discharge power as low as $5 \mathrm{~W}$. This is a perfect illustration of low power consumption, low cost for fabrication of the DBD atomizer which can be applied as a field portable analytical instrument with a battery as the power supply.

The shield gas is also crucial for maintaining atomization efficiency by avoiding air entering into the atomizer. The flow rate of the shield gas was examined in the range of 800 to $1100 \mathrm{~mL} \mathrm{~min}^{-1}$. The signal was increased from 800 to $1100 \mathrm{~mL} \mathrm{~min}^{-1}$, and the optimum signal-to-background ratio was obtained at a shield gas

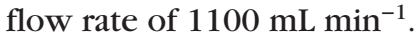

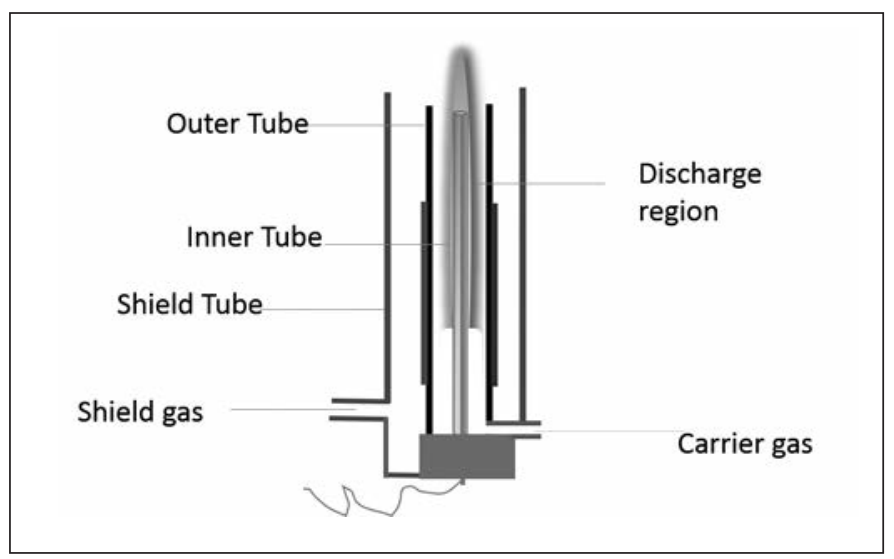

Fig. 1. The schematic diagram of the DBD atomizer.

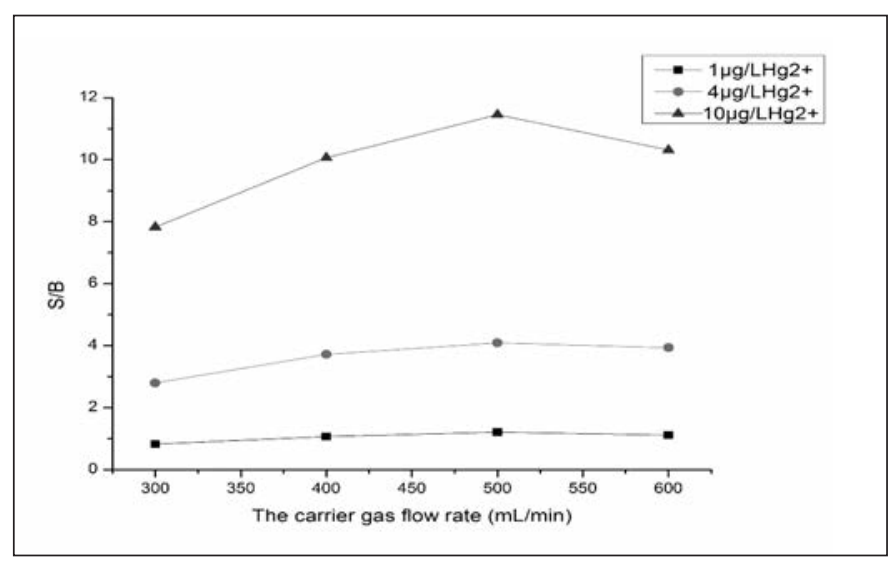

Fig. 2. Optimization of the carrier gas flow rate. 


\section{Atomic Spectroscopy \\ $\bigcirc$ Vol. 40(2), March/April 2019}

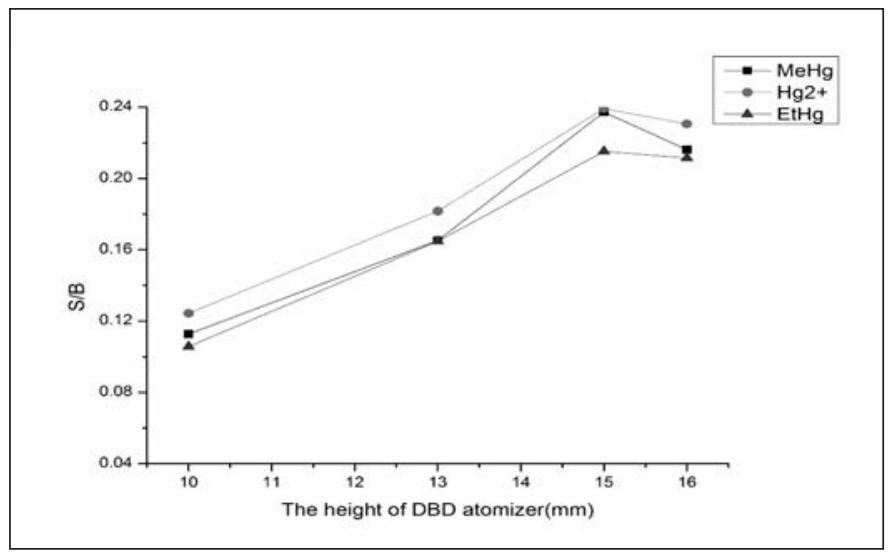

Fig. 3. Optimization of the beight of DBD atomizer.

TABLE I

Optimal Instrumental Parameters of HPLC-CVG-DBD-AFS

\begin{tabular}{lr}
\hline Parameters & \multicolumn{1}{c}{ Value } \\
\hline Carrier gas flow rate & $500 \mathrm{~mL} \mathrm{~min}^{-1}$ \\
Shield gas flow rate & $1100 \mathrm{~mL} \mathrm{~min}^{-1}$ \\
DBD atomizer height & $15 \mathrm{~mm}^{\circ}$ \\
Discharge power & $5 \mathrm{w}$ \\
$\mathrm{KBH}_{4} / \mathrm{NaOH}$ & $2 / 5 \mathrm{~g} \mathrm{~L}^{-1}$ \\
$\mathrm{HCl}(\mathrm{v} / \mathrm{v})$ & $5 \%$ \\
$\mathrm{~K}_{2} \mathrm{~S}_{2} \mathrm{O}_{8} / \mathrm{NaOH}$ & $2 / 5$ \\
$\mathrm{~L}-\mathrm{cysteine}$ & $3 \mathrm{~g} \mathrm{~L}^{-1}$ \\
Methanol (v/v) & $5 \%$ \\
Ammonium acetate & $4.62 \mathrm{~g} \mathrm{~L}^{-1}$ \\
PMT voltage & $380 \mathrm{~V}$ \\
Hollow cathode lamp & $60 \mathrm{~mA}$ \\
current &
\end{tabular}

\section{Optimization of the HPLC}

The composition of the mobile phase has an effect on the separation of $\mathrm{Hg}^{2+}, \mathrm{MeHg}$, and $\mathrm{EtHg}$. To achieve baseline separation for the three mercury species, the L-cysteine was used as a chelating agent in the mobile phase to form a coordinated complex with the mercury species, and was then separated on a chromatographic column in the methanol mobile phase. Furthermore, the ammonium acetate acted as a buffer to keep the $\mathrm{pH}$ stable in the mobile phase. In the present experiment and when the content of L-cysteine was changed from

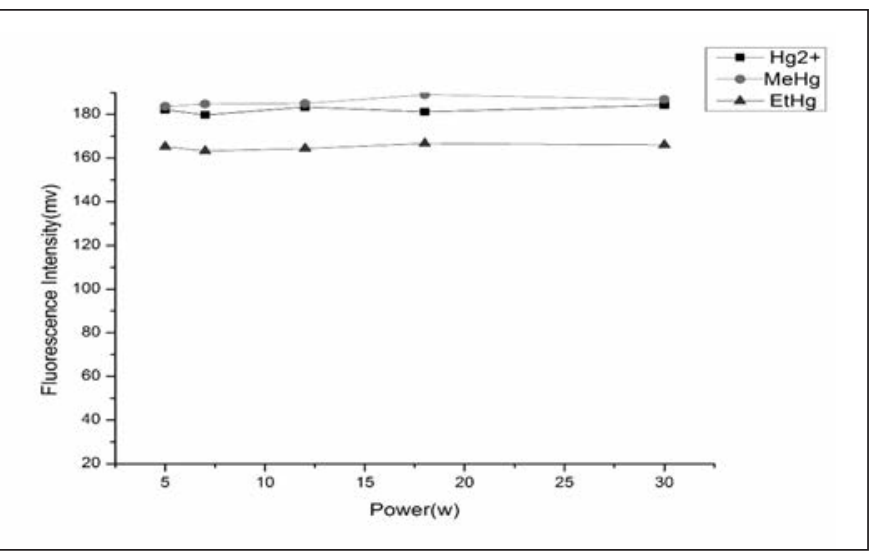

Fig. 4. Optimization of the plasma power.

TABLE II

The LOQ of Three Methods

\begin{tabular}{lccccc}
\hline & \multicolumn{3}{c}{$\begin{array}{c}\text { Limit of Minimum } \\
\text { Quantitation (LOQ) } \\
\left(\mu \mathrm{L} \mathrm{L}^{-1}\right)\end{array}$} & $\begin{array}{c}\text { Certified } \\
\text { Value } \\
\left(\mu \mathrm{L} \mathrm{L}^{-1}\right)\end{array}$ & $\begin{array}{c}\text { Determined } \\
\text { Value } \\
\left(\mu \mathrm{L}^{-1}\right)\end{array}$ \\
$\begin{array}{l}\mathrm{Hg}^{2+} \\
\mathrm{MeHg}\end{array}$ & $\mathrm{EtHg}$ & $\begin{array}{c}\mathrm{GBW10029} \\
(\mathrm{MeHg})\end{array}$ & $\begin{array}{c}\mathrm{GBW10029} \\
(\mathrm{MeHg})\end{array}$ \\
\hline Cold AFS (fire off) & 0.233 & 0.309 & 0.406 & $840 \pm 30$ & $818.9 \pm 21.2$ \\
Cold AFS (fire on) & 0.040 & 0.039 & 0.042 & & $846.7 \pm 16.4$ \\
HPLC-CVG- DBD-AFS & 0.084 & 0.086 & 0.093 & & $831.6 \pm 18.0$ \\
\hline
\end{tabular}

0.8-4.0 $\mathrm{g} \mathrm{L}^{-1}$, it was observed that the retention time and tailing peak of the three mercury species reduced with an increase in L-cysteine concentration. However, a complete baseline-resolved peak cannot be achieved with a further increase in L-cysteine concentration. A concentration of $3 \mathrm{~g} \mathrm{~L}^{-1}$ L-cysteine was selected for subsequent experiments due to a short separation time and good resolution of the chromatographic peaks. The optimum conditions used are listed in Table I accordingly.

\section{Analytical Performance}

The analytical performance of the developed HPLC-CVG-DBD-AFS method for the simultaneous determination of $\mathrm{Hg}^{2+}, \mathrm{MeHg}$, and $\mathrm{EtHg}$ was evaluated under optimum conditions. With peak area as the analytical parameter, the calibration curves were linear for the $\mathrm{Hg}^{2+}$,
$\mathrm{MeHg}$, and EtHg concentrations ranging from 0.5 to $10 \mu \mathrm{g} \mathrm{L}^{-1}(\mathrm{R}>$ 0.999) (see Figure 5) and shows good linear correlation with the concentrations. The limits of minimum quantitation (LOQ) for the three methodologies of Cold AFS (fire off), Cold AFS (fire on), HPLCCVG-DBD-AFS and measurement of the certified reference material GBW10029 Fish are listed in Table II. The results indicate that with the cold AFS method, the LOQ is affected with "fire on". The LOQ was fairly high when the fire was turned off. It can be assumed and speculated that the water formed by the reaction of the $\mathrm{KBH}_{4}$ solution with the $\mathrm{HCl}$ solution may influence the stability of the atomic fluorescence signal. In contrast, the LOQ and the signal stability of the mercury atomic vapor is almost not influenced at room temperature by the water with the HPLC-CVG-DBDAFS. We can speculate that the 


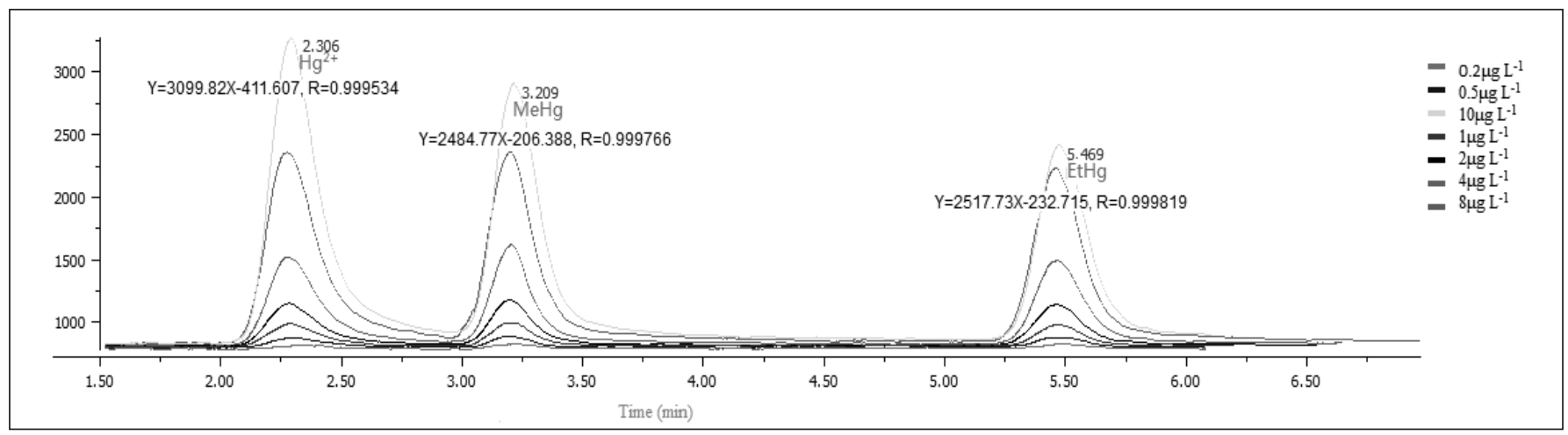

Fig. 5. The typical chromatograms of different concentrations for $\mathrm{Hg}^{2+}, \mathrm{MeHg}$, and $\mathrm{EtHg}$.

water may be reduced by the free radicals or other activated particles of the DBD devices. Furthermore, the relative standard deviations (RSDs, $\mathrm{n}=7$ ) obtained from $8 \mu \mathrm{g} \mathrm{L} \mathrm{L}^{-1}$ $\mathrm{Hg}^{2+}, \mathrm{MeHg}$, and EtHg were $4.8 \%$, $3.7 \%$, and $3.9 \%$, respectively, again in conformity with the conjecture. After comprehensive analysis, it can be stated that the modified method presented in this study has a vast application potential in the speciation analysis of mercury on-line as well as for use in the field as a portable/miniaturized instrument.

\section{CONCLUSION}

A modified HPLC-CVG-DBD-AFS method is presented for the speciation of mercury which achieves good sensitivity and stability, is comparable to the results of a commercial AFS instrument, and could be extended to selenium and arsenic speciation analysis. Furthermore, the modified method has displayed a vast application potential in a miniaturized and portable instrument due to the signal stability of the mercury where atomic vapor is almost not influenced by water at ambient-temperature operation. Related work is underway in our laboratory.

\section{ACKNOWLEDGMENT}

The authors are grateful for the financial support by the National Natural Science Foundation of
China (NSFC No. 41703132 , 21565013, 21575075) and the National Key Research and Development Program of China (No. 2016YFE0203000, 2017YFD0801202, and 2017YFD0800304).

Received October 17, 2018.

\section{REFERENCES}

1. Z. Zou, Y. Deng, J. Hu, X. Jiang, and X.Hou, Anal. Chim. Acta 1019(12), 25 (2018).

2. X. B. Yin, X.Y. Wang, S. Chen, Y. Ma, K. Guo, and Z.G. Zeng, At. Spectrosc. 39(4), 137 (2018)

3. D. Bakircioglu, N. Topraksever, S. Yurtsever, and Y.B. Kurtulus, At. Spectrosc. 39(1), 38 (2018).

4. W. Guo, L.L. Jin, S.H. Hu, and Q.H. Guo, J. Agri. Food Chem. 65, 3406 (2017).

5. D.Y. Tao, W. Guo, W.K. Xie, L.L. Jin, Q.H. Guo, and S.H. Hu., Microchem. J. 135, 221 (2017).

6. W. Guo, Z.W. Wu, S.H. Hu, L.L. Jin, K.Y. Qiu, and Q.H. Guo, Rsc. Adv. 6, 47394 (2016).

7. X.J. Wang, L.L. Jin, W. Guo, L.Q. Huang, and S.H. Hu, At. Spectrosc. 38(1), 44(2017).

8. W. Guo, Z.W. Wu, S.H. Hu, L.L. Jin, K.Y. Qiu, and Q.H. Guo,
Rsc. Adv. 6, 47394 (2016).

9. S. Khan, M. Soylak, R.M. Alosmanov, T. G. Kazi, and S.A. Sheikh, At. Spectrosc. 39(4), 158 (2018).

10. Y.T. Li, W. Guo, Z.W. Wu, L.L. Jin, Y.Q. Ke, Q.H. Guo, and S.H. Hu, Microchem. J. 126, 194 (2016).

11. Y.E. Peng, W. Guo, J. Zhang, Q. H. Guo, L. L. Jin, and S. H. Hu, Microchem. J. 124, 127 (2016).

12. W. Guo, Y. X. Wang, J. X. Li, Y. E. Peng, L. L. Jin, Q. H. Guo, and S. H. Hu, At. Spectrosc. 37, 7 (2016).

13. W. Guo, W.K. Xie, L.L. Jin, Q. H. Guo, and S. H. Hu, Rsc. Adv. 5, 103189 (2015).

14. W. Guo, S.H. Hu, Z.W. Wu, G.Y. Lan, L.L. Jin, X.G. Pang, J.C. Zhan, B. Chen, and Z.Y. Tang, J. Anal. At. Spectrom. 30, 986 (2015).

15. Q. Xu, W. Guo, L.L. Jin, Q.H. Guo, and S.H. Hu, J. Anal. At. Spectrom. 30, 2010 (2015).

16. Z.W. Wu, W. Guo, L.L. Jin, and S.H. Hu, Microchem. J. 142, 251 (2018).

17. E. Bagda, M. Tuzen, A. Sari, A.M. Shemsi, At. Spectrosc. 39(4), 170 (2018).

18. D. Sanchez-Rodas, W. Corns, B. Chen, and P. Stockwell, J. Anal. At. Spectrom. 25 (2010). 
19. D.J. Butcher, Appl.

Spectrosc. Rev. 51 (2016).

20. K. Leopold, M. Foulkes, and P. Worsfold, Anal. Chim. Acta 663(11), 127 (2010).

21. T. Syversen and P. Kaur, J. Trace Elem. Med. Biol. 26(11), 215 (2012).

22. W. L. Clevenger, B. W. Smith, and J. D. Winefordner, Crit. Rev. Anal. Chem. 27(25), 1 (1997).

22. W. L. Clevenger, B. W. Smith, and J. D. Winefordner, Crit. Rev. Anal. Chem. 27(25), 1 (1997).

23. Z.F. Liu, Z. Xing, Z.Y. Li, and Z.L. Zhu, J. Anal. At. Spectrom. 32, 678 (2017).

24. Y. Lin, Y. Yang, Y. X. Li, L. Yang, X. D. Hou, X.B. Feng, and C.B. Zheng, Environ. Sci. Technol. 50, 2468 (2016).

25. Y. Chen, X. Cheng, F. Mo, L. Huang, Z. Wu, Y. Wu, L. Xu, and F. $\mathrm{Fu}$, Electrophoresis 37(7-8), 1055 (2016).

26. P. Jitaru and F. Adams, J. Phys. IV France. 121, 185-193 (2004).

27. Y. G. Yin, J. F. Liu, B. He, E. L. Gao, and G. B. Jiang, J. Anal. At. Spectrom. 22, 822-826 (2007).

28. E. Gao and J. S. Liu, Anal. Sci. 27, 637-641 (2011).

29. X. Ai, Y. Wang, X. D. Hou, L. Yang, C. B. Zheng, and L. Wu, Analyst 138, 3494-3501 (2013).

30. Z. J. Yun, B. He, Z. H. Wang, T. Wang, and G. B. Jiang, Talanta 106, 60-65 (2013).

31. D. P. C. de Quadros, B. Campanella, M. Onor, E. Bramanti, D. L. G. Borges, and A. D'Ulivo, Spectrochim. Acta Part B 101, 312319 (2014).

32. G. Leng, W. J. Chen, and Y. Wang, J. Sep. Sci. 38, 2684-2691 (2015).
33. Y. G. Yin, Z. H. Wang, J. F. Peng, J. F. Liu, B. He, and G. B. Jiang, J. Anal. At. Spectrom. 24, 1575-1578 (2009).

34. Y. Gao, Z. M. Shi, Z. Long, P. Wu, C. B. Zheng, and X. D. Hou, Microchem. J. 103, 1-14 (2012).

35. D. P. C. de Quadros, B. Campanella, M. Onor, E. Bramanti, D. L. G. Borges, and A. D'Ulivo, Spectrochim. Acta Part B 101, 312319 (2014).

36. Z. Xing, B. Kuermaiti, J. Wang, G.J. Han, S.C. Zhang, and X. R. Zhang, Spectrochimica Acta Part B 65, 1056-1060 (2010).

37. Z. Xing, J. Wang, S.C. Zhang, and X.R. Zhang, Talanta 80, 139142 (2009).

38. S. Burhenn, J. Kratzer, M. Svoboda, F. D. Klute, A. Michels, D. Veza, and J. Franzke, Anal. Chem. 90 (5), 3424-3429 (2018).

39. H. Zheng, J. Ma, Z. Zhu, Z. Tang, and S. Hu, Talanta 132, 106111 (2015).

40. C. Meyer, S. Muller, E.L. Gurevich, and J. Franzke, Analyst 136, 2427 (2011).

41. S. Liu, Y.L. Yu, and J.H. Wang, J. Anal. At. Spectrom. 32, 2118 (2017).

42. Z. Zhu, S. Zhang, J. Xue, and X. Zhang, Specrochim. Acta Part B. 61, 916 (2006).

43. Y.H. He, Y. Lv, Y.M. Li, H.R. Tang, L. Tang, X. Wu, and X.D. Hou, Anal. Chem. 79, 4674-4680 (2007).

44. Z.1. Zhu, Z.F. Liu, H.T. Zheng, and S.H. Hu, J. Anal. At. Spectrom. 25, 697-703 (2010).

45. J. Kratzer, J. Bousek, R.E. Sturgeon, Z. Mester, and J. Dedina, Anal. Chem. 86, 9620-0625 (2014).

46. Z.Zhu, S. Zhang, Y. Lv, and X. Zang, Anal. Chem. 78, 865-872 (2006).

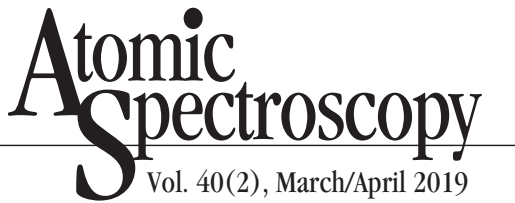

47. O. Duben, J. Bousek, J. Dedina, and J. Kratzer, Spectrochim. Acta Part B. 111, 57-63 (2015).

48. Q. Wu, Z. Zhu, J. Liu, H. Zheng, S. Hu, and L. Li, J. Anal. At. Spectrom. 27, 496-500 (2012).

49. Y.L. Yu, Z. Du, M.L. Chen, and J.H. Wang, J. Anal. At. Spectrom. 23, 493-499 (2008).

50. Z. Liu, Z. Zhu, Q. Wu, S. Hu, and $\mathrm{H}$. Zheng, Analyst 136 (21), 4539-4544 (20110. 